\title{
Silica Nanoparticles and pH effect on Sand Production Mechanism due to Smart Water Softening
}

\author{
Masoud Bijani $^{1}$ (D), Ehsan Khamehchi 1,* (D), Shoaib Ezzati ${ }^{1}$ (D) \\ 1 Department of Petroleum Engineering, Amirkabir University of Technology, Tehran, Iran \\ * Correspondence khamehchi@aut.ac.ir;
}

Received: 12.06.2020; Revised: 3.07.2020; Accepted: 4.07.2020; Published: 7.07.2020

\begin{abstract}
Low salinity water is the most common method of increasing oil production, which has become very common in recent decades. Low-salinity water changes the electric charge of the rock surface in sandstone and carbonate reservoirs, causing the rock to become water wet. By a salt shock, smart water disturbs the static balance of sandstone reservoirs and increases sand production. Stabilizing nanoparticles in smart water can create a nano texture on the rock surface and change its wettability. On the other hand, by sitting on the rock surface in the sandstone reservoirs, they increase the strength of the rock and greatly reduce sand production. One way to improve the properties of low-salt water is to remove magnesium and calcium ions, which can be produced by using smart soft water, which has the ability to increase water viscosity, easier absorption of surfactants, and in any case, smart soft water has higher efficiency and more economical. The purpose of this study is to investigate sand production, with used $\mathrm{SiO}_{2}$ nanoparticles at different $\mathrm{pH}$. By potential zeta test, $1000 \mathrm{ppm} \mathrm{SiO}_{2}$ concentration was selected for testing. The $\mathrm{pH}$ value of five containers containing smart soft water And five other containers containing Nanofluid was adjusted to 4.5, 5.5, 6.5, 7.5, and 8.5. In each of the ten containers, a thin section with a specific weight was immersed. After measuring the daily weight of the thin sections for five days, we concluded that the use of $\mathrm{SiO} 2$ nanoparticles, $80 \%$, and a change of four $\mathrm{pH}$ units, $75 \%$, would prevent sand production.
\end{abstract}

Keywords: sand production; solution $\mathrm{pH}$; zeta potential; Nanoparticles; smart soft water.

(c) 2020 by the authors. This article is an open-access article distributed under the terms and conditions of the Creative Commons Attribution (CC BY) license (https://creativecommons.org/licenses/by/4.0/).

\section{Introduction}

In sandstone reservoirs that are not placed between the grains of sand, cement, with the production of oil, the grains of sand begin to be produced, which is called sand production. Sand production is one of the main problems of sandstone reservoirs [1]. Sand production causes many problems in oil reservoirs, greatly increases the cost of maintaining and cleaning wells, and causes problems in all areas where oil moves. Inside the reservoirs, it reduces the permeability and blocking of the porous medium and may destroy the equipment that prevents sand production. Also, inside the well, they cause corrosion and damage to valves and chokes. And in very severe cases, they may cause the well to become inaccessible. Therefore, methods should be used to prevent sand production from increasing the strength of the moraine rock [24].

There are several ways to prevent sand production, which are divided into active and inactive. In active methods, various equipment is used to prevent sand production [5-8]. Moreover, in inactive methods, try to increase the rock strength. One of the inactive methods 
is to use resin, which greatly reduces permeability. Another inactive method is the use of nanoparticles, which can increase the rock strength and prevent sand production by stabilizing it in smart water [9-11]. Smart water is an Increasing oil production method introduced in 1967 [12] and made significant advances in the 1990s, making it the most common method of increasing oil production. Smart water increases the oil recovery factor by several mechanisms, the most important of which is wettability alteration [13-16].

Using smart water increases sand production. The reason for this increase in sand production could be surface changes in rock [17-20]. Different nanoparticles can control sand production. Moreover, because they do not reduce permeability, they have received much attention in recent years. Stabilizing nanoparticles in smart water creates major changes in water characteristics that can be severely influences in oil reservoirs [21-24]. On the other hand, various studies have shown that the use of nanoparticles can greatly reduce the migration of fine particles [25][26].

Smart water is very economical, but it can be improved and produced more efficiently. Soft water production has been considered in recent studies. Soft water production has been considered in recent studies. By removing calcium and magnesium ions, soft water can be produced that can cause major changes in the rock surface. A comparison in 2014 have been made, the effect of soft water on increasing the recovery factor of the oil factor was much higher than hard water. Mohammadi Jerauld also found that by combining low salinity water and polymer, water viscosity is increased, and by increasing viscosity of injected water, the oil recovery consequently increased [27]. Soft water is a water that does not contain calcium and magnesium ions and has been used for such reasons as better polymer stability, surfactant absorption, and increased viscosity [28].

In this present, by wisely choosing soft water ions, we produced smart soft water (SSW) and investigated their impact on the sand production from sandstone samples that had certain properties. For this review, first, we mixed three types of smart water with formation water, and by Minitab software, we choose the composition of soft water that has the least amount of incompatibility with formation water. Then we used silica nanoparticles at different concentrations and selected the most stable concentration in soft water as nanofluid. And adjusted the $\mathrm{pH}$ of the obtained nanofluid and optimized soft water. Finally, thin Sections that we got from the sandstone plug immersed in the smart soft water (SSW) with and without nano and measure the amount of sand production. We got some interesting results that, in the following, we examine these results and experiments.

\section{Materials and Methods}

\subsection{Materials}

\subsubsection{Minerals.}

For this experiment, we used $3 \mathrm{~mm}$ thick, thin sections were made of plugs that had certain petrophysical properties. We can see the mineralogy of the rock components (thin sections) used in Table 1.

Table 1. Mineralogy of sands from XRF measurements.

\begin{tabular}{l|l|l|l|l|l|l|l|l|l} 
Elements & $\mathbf{S i O}_{2}$ & $\mathbf{A l 2 O}_{3}$ & $\mathbf{C a O}$ & $\mathbf{F e}_{2} \mathbf{O}_{3}$ & $\mathbf{K}_{2} \mathbf{O}$ & $\mathbf{M g O}$ & $\mathbf{N a}_{2} \mathbf{O}$ & $\mathbf{S O}_{3}$ & $\mathbf{L O I}$ \\
\hline Sand (\%) & 78.81 & 8.95 & 2.42 & 0.55 & 3.16 & 0.21 & 1.74 & 1.47 & 2.58 \\
\hline Cement (\%) & 20.73 & 4.12 & 61.91 & 3.25 & 0.078 & 3.26 & 0.35 & 2.39 & 2.49
\end{tabular}




\subsubsection{Brines.}

Formation water (One of the southern Iran reservoirs), and Seawater (Persian Gulf) were prepared in the laboratory using chemicals purchased from Merck laboratories. Deionized water was used for the brine preparation, having total organic content $<5 \mathrm{ppb}$ and resistivity of $18.2 \mathrm{M} \Omega \mathrm{cm}$, and it was one-time evaporation. An incompatibility test was used to produce soft water.

The Persian Gulf water was diluted 5, 10, and 15 times and was mixed with each of them with an equal volume of formation water. And were placed on a magnetic stirrer for 30 $\min$, then $24 \mathrm{~h}$ in reservoir simulator temperature. Moreover, by measuring the mass of the sediments, it was found that water was ten times diluted had the least sediment. Then, using the Minitab software and Taguchi's algorithm, we obtained a soft water composition. All properties of formation water, seawater, and soft water are given in Table 2.

Table 2. Composition of formation water, seawater, and soft water.

\begin{tabular}{|c|c|c|c|c|}
\hline Components & $\begin{array}{l}\text { Formation water } \\
\text { weight }(\mathrm{g} / \mathrm{l})\end{array}$ & $\begin{array}{ll}\begin{array}{l}\text { Sea } \\
\text { weight }(g / l)\end{array} & \text { water } \\
\end{array}$ & $\begin{array}{l}\text { Soft } \\
\text { weight }(g / l)\end{array}$ & Manufacturer \\
\hline $\mathrm{NaCl}$ & 150 & 28 & 2.1 & Merck \\
\hline $\mathrm{CaCl}_{2} \cdot 6 \mathrm{H}_{2} \mathrm{O}$ & 49.5 & 1.38 & ---------- & Merck \\
\hline $\mathrm{NaHCO}_{3}$ & 0.66 & 0.1 & 0.015 & Merck \\
\hline $\mathrm{KCl}$ & 0 & 0.8 & 1.44 & Merck \\
\hline $\mathrm{MgCl}_{2} .6 \mathrm{H}_{2} \mathrm{O}$ & 14.5 & 5.5 & ----------- & Merck \\
\hline $\mathrm{Na}_{2} \mathrm{SO}_{4}$ & 0.403 & 4.4 & 0.44 & Merck \\
\hline
\end{tabular}

\subsubsection{Other materials.}

$\mathrm{The} \mathrm{SiO}_{2}$ nanoparticles were used for testing had an average particle size of about 25 $\mathrm{nm}$. We used stearic acid (with molar mass $248.48 \mathrm{~g} / \mathrm{mol}$ and density $941 \mathrm{~kg} / \mathrm{m} 3$ ) and normal heptane (with molar mass $100.21 \mathrm{~g} / \mathrm{mol}$ and density $684 \mathrm{~kg} / \mathrm{m} 3$ ) for oil wetting thin sections. Furthermore, for setting the value of $\mathrm{pH}$, we used $\mathrm{HCl}$ and $\mathrm{NaOH}$.

\subsection{Methods.}

\subsubsection{Thin section.}

The plug that was selected for this experiment was transformed into a $3 \mathrm{~mm}$ thick, thin section by a cutting machine. For this test, ten thin sections were required, and among the available thin sections, the best thin sections were selected.

\subsubsection{Oil wetting procedure.}

The amount of thin sections wettability is unknown and may affect the sand production, so we decided to oil wetted all thin sections. Normal heptane and stearic acid were used to oil wetted ten thin sections.

For oil wetted the samples, 500 ccs of $0.01 \mathrm{M}$ stearic acid solution were first made in normal heptane. We put ten samples of the required thin sections in this solution (as shown in Figure 1), and finally, It was placed in a reservoir temperature simulator (Oven) at $65^{\circ} \mathrm{C}$ for 72 hours. 


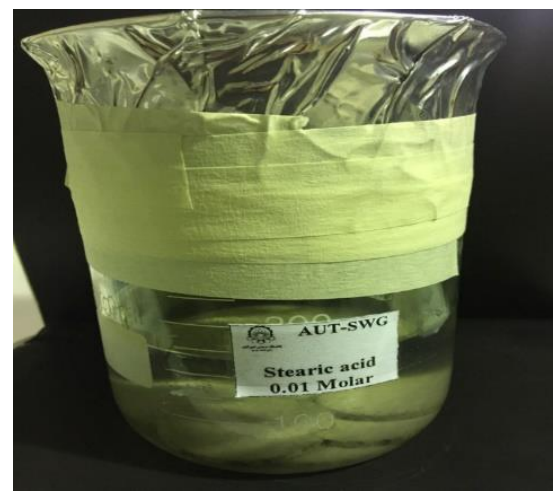

Figure 1. Submerging thin sections in normal heptane with 0.01 molar stearic acid.

\subsubsection{Drying procedure.}

After oil wetting the thin sections, for drying, we first set them at room temperature for 24 hours. Then they were placed in the reservoir temperature simulator (oven) at $65^{\circ} \mathrm{C}$ for 2 hours until completely dried, and their residual water saturation reaches zero (In Figure 2, preparation of the thin sections for drying can be seen). After completing these steps, the thin sections were prepared for weighing.

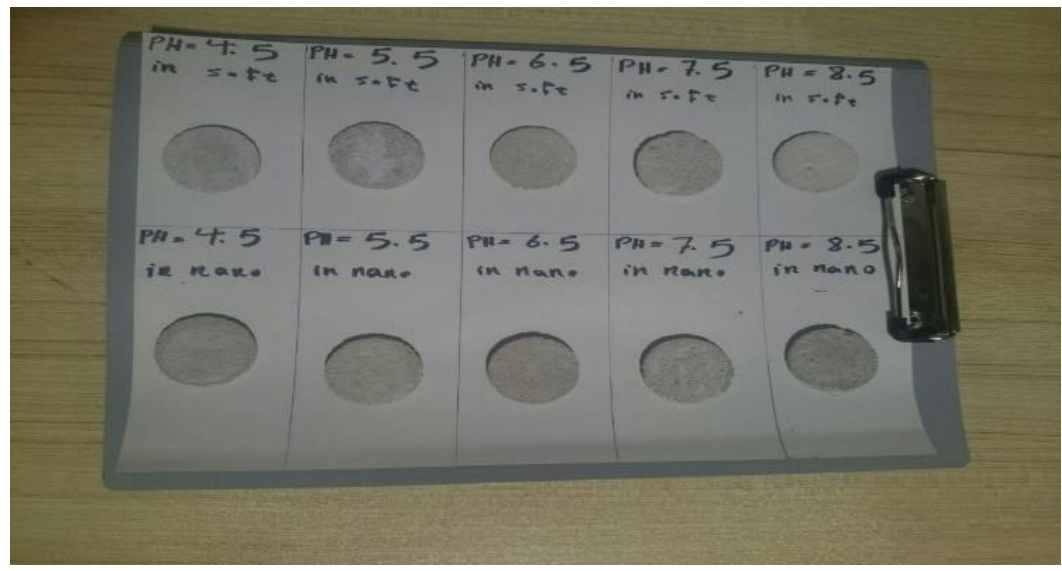

Figure 2. Prepare thin sections for drying.

\subsubsection{Nanofluid preparation.}

For this experiment, $\mathrm{SiO}_{2}$ nanoparticles were used. These nanoparticles were selected for three reasons: 1. most previous studies on enhanced oil recovery and prevention of fines migration have obtained acceptable results from this nanoparticle. 2. $\mathrm{SiO}_{2}$ easily becomes stable in water and does not require polymer, surfactant, or other additives. 3 . Because the silica nanoparticles are similar to sandstone, it sits easily on the rock and preventing further sand production. In this sense, it was easy to see the boundary between using nano and not using nano in experiments.

To prepare the nanofluids, first $1000 \mathrm{cc}$ of SSW was made and poured in two containers (each one contain $500 \mathrm{cc} \mathrm{SSW}$ ), after this, $0.5 \mathrm{~g}$ And $0.25 \mathrm{~g}$ of $\mathrm{SiO}_{2}$ nanoparticles were poured into containers each containing $500 \mathrm{ccs}$ of SSW and then placed on a magnetic stirrer (with speed range about 1800rpm) for 30min and sonicated (a sonicated device with $24 \mathrm{kHz}$ frequency and $400 \mathrm{w}$ power) for 1 hour. Both Nano-fluids were visually stable, and we could not select which one was more suitable for testing. To distinguish between the two concentrations of 1000 and $500 \mathrm{ppm}$, we had to use the potential zeta test. Zeta potential test 
was performed to determine the zeta potential and the average diameter of the particles in the nanofluid.

\subsection{5. $\mathrm{pH}$ measurement.}

According to Table 1, 500cc SSW was made and poured in five beakers, and $500 \mathrm{ccs}$ of soft water with nano was poured in the other five beakers (each beaker contains 50cc of fluid). We adjusted the $\mathrm{pH}$ value of each of five SSW samples and every five Nanofluid samples to values of 4.5, 5.5, 6.5, 7.5, and 8.5. To adjust the $\mathrm{pH}$ value, we used $\mathrm{HCl}$ and $\mathrm{NaOH}$.

\subsubsection{Weighing of sand production.}

Thin sections that fully oil wetted and was kept in the reservoir temperature simulator (Oven) for two hours, they were weighed by a digital scale with an accuracy of $0.01 \mathrm{mg}$. Then we put each of the thin sections in the beakers with the specifications on the glasses. Thus, in each of the ten beakers containing SSW with and without Nano, a specific thin section was inserted. We put aluminum foil on the beakers to isolate the solution in those. We placed all beakers in a reservoir temperature simulator (Oven), and set the oven temperature at $65^{\circ} \mathrm{C}$.

After 24 hours, we tacked out the samples from the reservoir temperature simulator and, with very high sensitivity, tacked out the thin sections from SSW beakers and SSW with Nano beakers (Nanofluid beakers), and to dry we placed all thin sections in a reservoir temperature simulator (oven) at $65^{\circ} \mathrm{C}$ for two hours, we dried completely and measured the weight of the dried thin sections. And again, the thin sections were put in their beakers and put in the oven at $65^{\circ} \mathrm{C}$ for the second 24 hours. Repeat the above steps for another four days and measure the weight of the dried thin sections daily. Generally, the thin sections were in the SSW with Nano and without Nano solution at reservoir temperature for five days (120 hours).

\section{Results and Discussion}

By reducing the $\mathrm{pH}$ of the injection water, the dissolution of the minerals increases, and thus the strength of the rock decreases, which greatly increases the production of sand in the sandstone reservoirs. This dissolution of minerals causes extensive changes in the amount of $\mathrm{pH}$, which affects the properties of smart water. On the other hand, $\mathrm{pH}$ is inversely related to permeability, by increasing the $\mathrm{pH}$, the permeability decreases with the changes that occur in the reservoir and the reason for the decrease in the permeability of fine migration that occurs due to the changes in $\mathrm{pH}[29,30]$.

In this study, the effect of different $\mathrm{pH}$ on sand production in the presence of nano and the absence of nano was investigated. To do this, the $\mathrm{pH}$ of the soft water was changed, and the sand production was measured. Then we changed the $\mathrm{pH}$ of the nanofluid, and the sand production was measured. Also, a comparison between the two modes (with nano and without nano) was performed to investigate the Nano effect and $\mathrm{pH}$ effect in soft water on sand production.

\subsection{Effect of $\mathrm{pH}$ on sand production in the absence of nano.}

The most common way to increase the oil recovery factor in oil reservoirs is to use low salinity water, or in other words, intelligently change the composition of the water, which causes wettability alteration of the reservoirs, which increases the relative permeability of the 
oil and moves easily [31-34]. Increasing the $\mathrm{pH}$ to above 8 reduces the surface tension of the oil and could be a reason for the increase in the oil recovery factor. However, an increase in $\mathrm{pH}$ in sandstone reservoirs is a problem that increases the fine migration [17][35-38].

But the effect of $\mathrm{pH}$ on sand production has not been investigated so far, and in this part of the study, the aim is to investigate sand production in different $\mathrm{pH}$ of soft water.

As mentioned, $500 \mathrm{ccs} \mathrm{SSW}$ was poured into five beakers (with the compounds listed in Table 1), and the $\mathrm{pH}$ of each beaker was adjusted to $4.5,5.5,6.5,7.5$, and 8.5 with $\mathrm{HCl}$ and $\mathrm{NaOH}$. The base weight of the thin sections measured before the test and shown in Table 3 .

Table 3. The Base weight of thin sections in SSW.

\begin{tabular}{l|l|l|l|l|l}
$\mathbf{p H}$ & $\mathbf{4 . 5}$ & $\mathbf{5 . 5}$ & $\mathbf{6 . 5}$ & $\mathbf{7 . 5}$ & $\mathbf{8 . 5}$ \\
\hline Weight $(\mathrm{g})$ & 8.87 & 8.7 & 8.91 & 8.67 & 8.62
\end{tabular}

After weighing, each thin section was inserted in a specified beaker and placed in a reservoir temperature simulator for 24 hours. Next, we review the sand production every 24 hours in the pHs that we set.

As shown in previous studies, the effect of $\mathrm{pH}$ on fine migration is such that as the environment becomes more acidic, the amount of fine migration decreases [39]. However, the case of sand production is different. In the presence of SSW, due to the absence of a barrier to sand production, the amount of production should be high as expected.

At $\mathrm{pH}=4.5$, as shown in Figure 3, the highest amount of sand produced was observed on the first day, and the total amount of sand produced was $0.16 \mathrm{~g}$ in the five days. From day 2nd to day 5th, the amount of sand production is gradually decreased, indicating that sand that has less cement is first produced. On the other hand, since there are no additives in soft water that inhibit the sand production, the presence of water decreases the consolidation of the grains, and a small amount of sand is produced every day. Generally, in $\mathrm{pH} 4.5,1.804 \%$ of sand production was observed, which is very high, but the reason for this sand production in an acidic environment may be that the acid can dissolve some of the rock components, and result in more sand produced.

At $\mathrm{pH}=5.5$, as shown in Figure 3, the amount of sand production is as high as $\mathrm{pH}=4.5$ and is $0.14 \mathrm{~g}$, which is $1.609 \%$ of the total thin section, which still was very high sand production.

At PH 6.5 and 7.5 (as shown in Figure 3), the sand production much lower than the previous values and is $0.12 \mathrm{~g}$ and $0.11 \mathrm{~g}$, respectively, which is $1.347 \%$ and $1.269 \%$ of the total thin sections produced.

At $\mathrm{pH}=8.5$ (as shown in Figure 3 ) due to the alkalinity of soft water and greater compatibility with thin section, it was observed that the amount of sand production was drastically reduced and $0.09 \mathrm{~g}$ of sand produced that was $1.045 \%$ of the total thin section.

As can be seen in SSW without any additives only by increasing $\mathrm{pH}$, the sand production reduced sharply And rose from 1.804 percent of the total rock to 1.045 percent of the rock. By increasing $\mathrm{pH}$ from 4.5 to 8.5 , the amount of sand production decreases about $75 \%$, and the effect of $\mathrm{pH}$ can be seen clearly.

\subsection{Effect of $p H$ on sand production in the presence of nano.}

In the previous section, the effect of smart soft water $\mathrm{pH}$ on sand production was observed. In this section, the production of sand with $\mathrm{pH}$ changes in the presence of nano is 
examined. Different nanoparticles are used in the oil industry in various fields, such as wettability alteration [40][41].

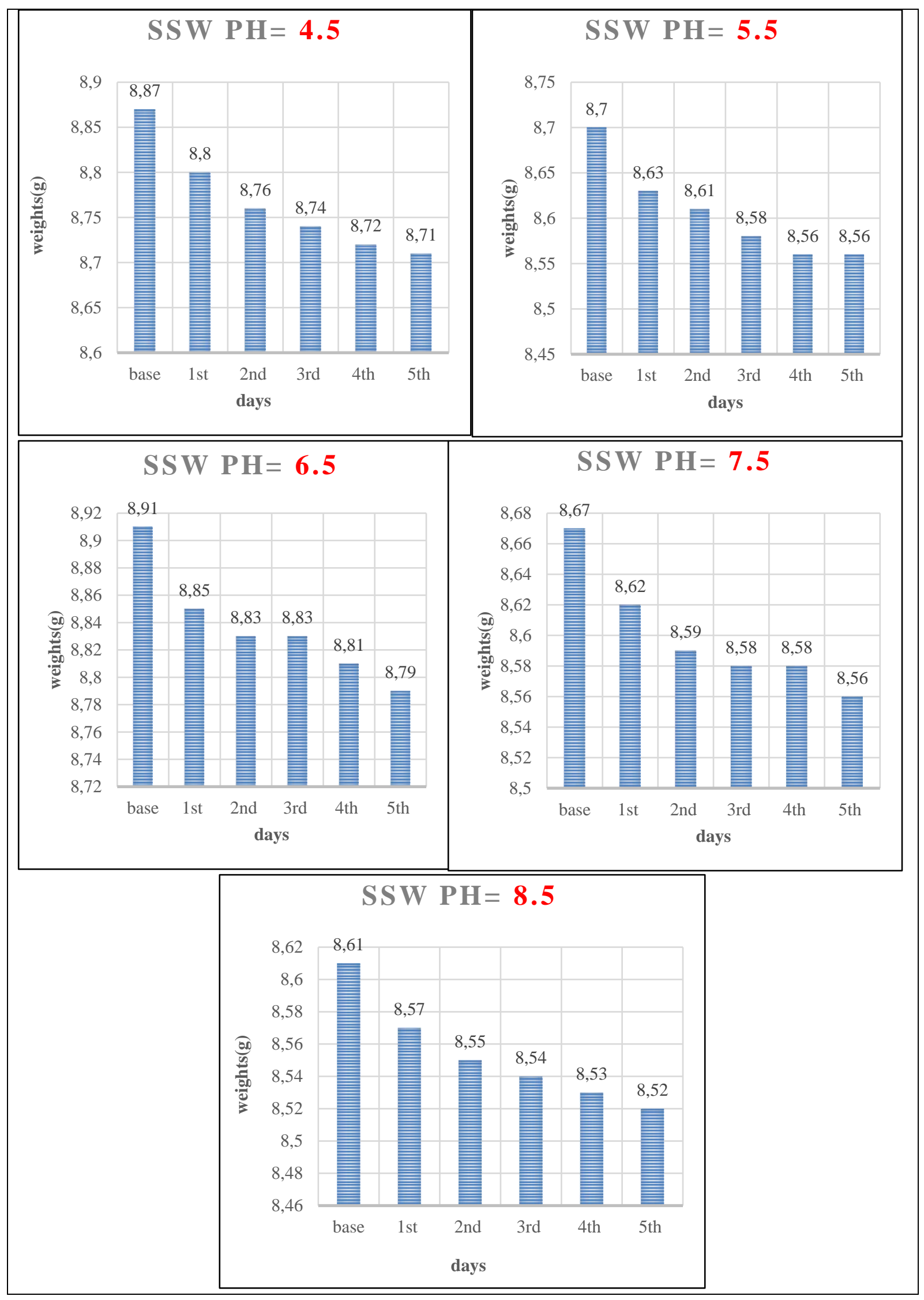

Figure 3. Effect of SSW pH on sand production in the absence of nano. 
To produce the desired nanofluid, we first need to provide a fluid that Nano stable in SSW, because if the nano precipitates, it will have a very low impact and will not be able to make chemical changes at the rock surface and will have little effect on sand production. There are two reasons to choose the best concentration for Nanofluid preparation: 1. The amount of nano used should be economical; that is, it should not exceed a specific limit. 2 . The amount of nano used should be capable of covering the surface of the sand grains. It means the amount of nano that used should not be less than a specific limit.

Based on these two conditions and studies carried out, concentrations of $1000 \mathrm{ppm}$ and $500 \mathrm{ppm}$ were selected. Stability was considered to select one of these concentrations. Zeta potential testing should be used to determine stability. This test was performed to determine the zeta potential of each sample and the mean diameter of suspended particles in each sample (Table 4).

Table 4. Result of potential zeta test.

\begin{tabular}{l|c|c|c} 
Nano fluid & Zeta potential $(\mathbf{m V})$ & Average diameter(nm) & Stability quality \\
\hline $\mathbf{1 0 0 0} \mathbf{~ p p m}$ & -30 & 207 & Very good \\
\hline $\mathbf{5 0 0} \mathbf{~ p p m}$ & -24 & 316 & good
\end{tabular}

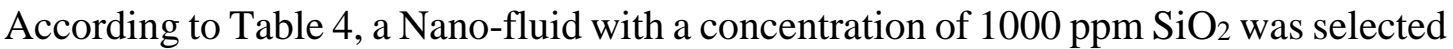
for the tests.

As mentioned, after performing the potential zeta test, it was found that the Nano-fluid with a concentration of $1000 \mathrm{ppm}$ had the best stability and was suitable for testing, then 50 ccs of Nano-fluid was put in each one of five beakers, and the beakers $\mathrm{pH}$ were adjusted to 4.5 , $5.5,6.5,7.5$ and 8.5. In each beaker was placed a thin section with a specific weight, as shown in Table 5 and placed in a reservoir temperature simulator (oven) to begin the experiments.

Table 5. The base weight of thin sections in SSW with Nano.

\begin{tabular}{l|l|l|l|l|l} 
pH & $\mathbf{4 . 5}$ & $\mathbf{5 . 5}$ & $\mathbf{6 . 5}$ & $\mathbf{7 . 5}$ & $\mathbf{8 . 5}$ \\
\hline Weight $(\mathrm{g})$ & 8.15 & 8.1 & 8.12 & 8.02 & 8.21
\end{tabular}

After 24 hours the samples were placed in the reservoir temperature simulator was tacked out, And, with high sensitivity, we removed the thin sections from the beakers, and accordance with Figure 2 were placed in the reservoir temperature simulator at $65^{\circ} \mathrm{C}$ for two hours. After drying of the thin sections, the weights of each of them were measured and placed in the specified glasses for the next 24 hours. Like the non-Nano tests, these experiments took 5 days, and after five days of weighing each thin section, we plotted the data, and now we analyze the graphs.

The presence of a nano should be able to cover the surface of the rock and the porous medium. One way to see if a nano can cover the surface of a rock is to use a microscope. Each of the thin sections was placed under a scanning electron microscope before being placed in the nanofluid, and their images were recorded. Furthermore, the comparison we made showed that the rock surface was well covered by nano. Figure 4 shows SEM images before and after immersion in the nanofluid. 


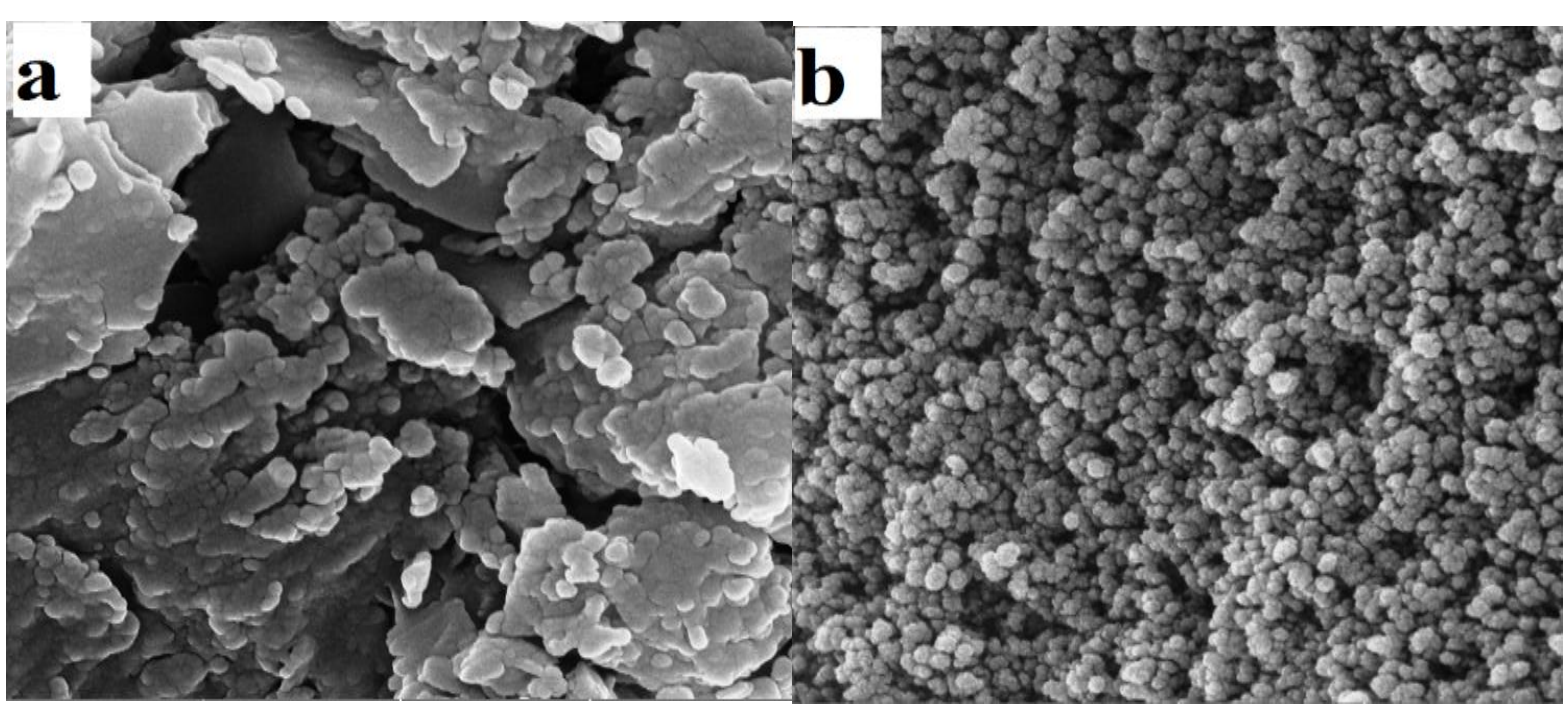

Figure 4. Rock surface submerging in the nanofluid, a) before submerging. b) after submerging.

As shown in Figure 5, at $\mathrm{pH}=4.5$, due to the acidity and possibly dissolution of some of the major rock constituents in this environment, the amount of sand production was high and produced about $0.08 \mathrm{~g}$, which is $0.982 \%$ of the total rock. Of this $0.08 \mathrm{~g}$ of sand, $0.05 \mathrm{~g}$ was produced on the first day, and $0.03 \mathrm{~g}$ only was produced in the second to fifth days. This is indicating the effect of silica nanoparticles on sand production.

At $\mathrm{pH}$ 5.5, 6.5 and 7.5 as seen in Figure 5, more sand production was in the first day, after which the sand production declined sharply, and at $\mathrm{pH}=5.5$ sand production was $0.741 \%$ of the total rock, and at $\mathrm{pH}=6.5$ and $\mathrm{pH}=7.5$ respectively sand production was $0.616 \%$ and $0.623 \%$ of the total rock.

At $\mathrm{pH}=8.5$, the amount of sand production is very low because the environment is more alkaline and stable, and the Nano effect prevents more sand production. In this $\mathrm{pH}, 0.487 \%$ of the total rock was produced, as shown in Figure 5, sand production in this $\mathrm{pH}$ was the lowest of all tests and this shows that the combination of increasing the $\mathrm{pH}$ to a certain amount and adding nano can be very good factors in preventing sand production.

\subsection{Comparison of the effect of nano and $\mathrm{pH}$.}

As can be seen in Figure 3 diagrams, although there is a lot of sand production on the first day, the diagrams have a slope in the following days, and there is some sand production per day. However, in the Figure 5 diagrams, more sand is produced on the first and second days, and then the dip of the graphs becomes zero, and this reflects the very good effect of silica nanoparticles, which, by chemical changes between the rock components, prevent from more sand production.

In Figure 6, we can clearly see the impact of Nanofluid 1000ppm $\mathrm{SiO}_{2}$. In this figure, the amount of sand production can be compared simultaneously in two modes (with nano and without nano) and different $\mathrm{pHs}$. Analyzing this figure, we can conclude that the average Nano effect was about $80 \%$ (average differential between with and without nano). That is, nano reduces sand production by up to $80 \%$. 


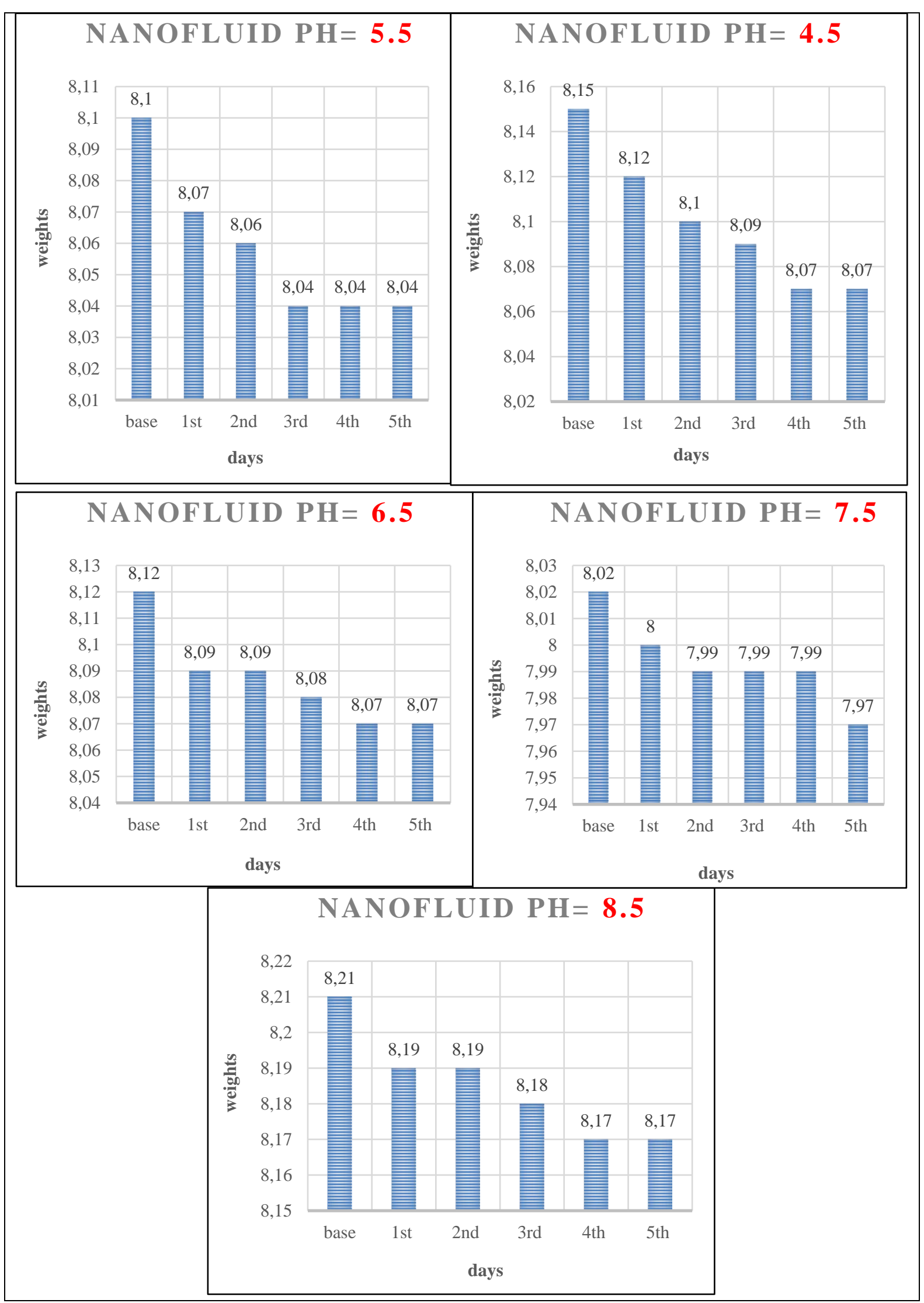

Figure 5. Effect of SSW pH on sand production in the presence of nano. 


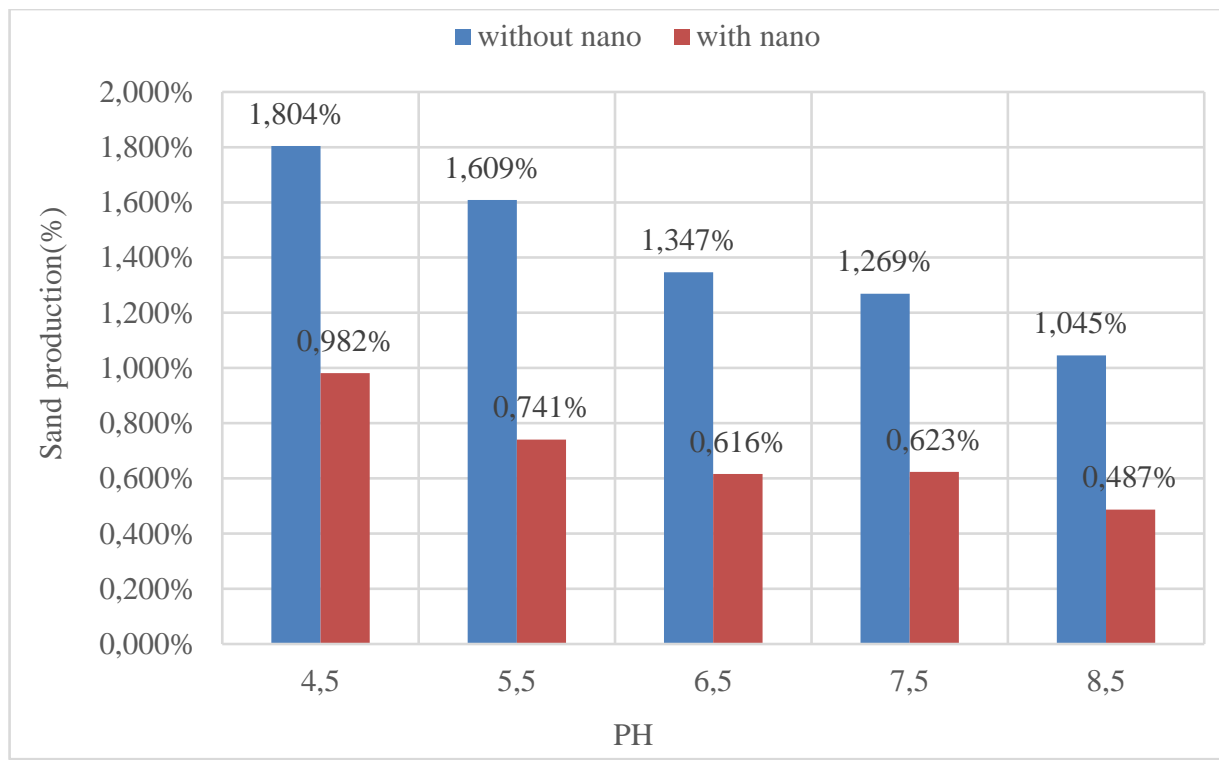

Figure 6. Comparison of sand production at different $\mathrm{pH}$.

By comparing the percentages of sand production in both modes(with nano and without nano), from $\mathrm{pH}=4.5$ to $\mathrm{pH}=8.5$, the amount of sand production in SSW reached from $1.804 \%$ to $1.045 \%$, and in nanofluid reached from $0.982 \%$ to $0.487 \%$. And this comparison, on average, shows about a $75 \%$ decrease in sand production with a change of four $\mathrm{pH}$ units.

\section{Conclusions}

Nanofluid has higher stability at $1000 \mathrm{ppm}$ concentration than $500 \mathrm{ppm}$. It can be said that there is no direct relationship between lower concentration and higher stability, and Nano stability cannot be detected visually .Most sand production was on the first and second days when unconsolidated sand was produced. After that, in the SSW, there was a gradual daily sand production, but in the SSW with Nano, the sand production was on the first and second days. After the first two days, sand production becomes zero. Since the experiments were performed in the presence of nano and the absence of nano, the effect of nano was clearly observed, and this effect was about $60 \%$, meaning that the use of $\mathrm{SiO}_{2}$ nanoparticles can reduce the production of sand by $60 \%$. In the two cases where the effect of $\mathrm{pH}$ was examined, both confirmed that as the $\mathrm{pH}$ increased, the amount of sand produced decreased, indicating that the results of the experiments were valid and reliable. The conclusion of this study is that the best way to prevent sand production is to use the silica nanoparticles concurrently and to increase the $\mathrm{pH}$ to a certain amount.

\section{Funding}

This research received no external funding.

\section{Acknowledgments}

This research has no acknowledgment.

\section{Conflicts of Interest}

The authors declare no conflict of interest. 


\section{References}

1. Aghajanzadeh, M.R.; Ahmadi, P.; Sharifi, M.; Riazi, M. Wettability modification of oil-wet carbonate reservoirs using silica-based nanofluid: An experimental approach. Journal of Petroleum Science and Engineering 2019, 178, 700-710, https://doi.org/10.1016/j.petrol.2019.03.059.

2. Youssif, M.I.; El-Maghraby, R.M.; Saleh, S.M.; Elgibaly, A. Silica nanofluid flooding for enhanced oil recovery in sandstone rocks. Egyptian Journal of Petroleum 2018, 27, 105-110, https://doi.org/10.1016/j.ejpe.2017.01.006.

3. Aghajanzadeh, M.R.; Ahmadi, P.; Sharifi, M.; Riazi, M. Wettability modification of oil-wet carbonate reservoirs using silica-based nanofluid: An experimental approach. Journal of Petroleum Science and Engineering 2019, 178, 700-710, https://doi.org/10.1016/j.petrol.2019.03.059.

4. Elazab, H.A.; El-Idreesy, T.T. Optimization of the catalytic performance of $\mathrm{Pd} / \mathrm{Fe} 3 \mathrm{O} 4$ nanoparticles prepared via microwave-assisted synthesis for pharmaceutical and catalysis applications. Biointerface Research in Applied Chemistry 2018, 9, 3794-3799, https://doi.org/10.33263/BRIAC91.794799.

5. Ejtemaee, P.; Khamehchi, E. Experimental investigation of rheological properties and formation damage of water-based. Biointerface Research in Applied Chemistry 2020, 10, 5886-5894, https://doi.org/10.33263/BRIAC104.886894.

6. Nowrouzi, I.; Manshad, A.K.; Mohammadi, A.H. Effects of ions and dissolved carbon dioxide in brine on wettability alteration, contact angle and oil production in smart water and carbonated smart water injection processes in carbonate oil reservoirs. Fuel 2019, 235, 1039-1051, https://doi.org/10.1016/j.fuel.2018.08.067.

7. Ko, S.; Huh, C. Use of nanoparticles for oil production applications. Journal of Petroleum Science and Engineering 2019, 172, 97-114, https://doi.org/10.1016/j.petrol.2018.09.051.

8. Ameli, F.; Moghbeli, M.R.; Alashkar, A. On the effect of salinity and nanoparticles on polymer flooding in a heterogeneous porous media: Experimental and modeling approaches. Journal of Petroleum Science and Engineering 2019, 174, 1152-1168, https://doi.org/10.1016/j.petrol.2018.12.015.

9. Saxena, N.; Kumar, A.; Mandal, A. Adsorption analysis of natural anionic surfactant for enhanced oil recovery: The role of mineralogy, salinity, alkalinity and nanoparticles. Journal of Petroleum Science and Engineering 2019, 173, 1264-1283, https://doi.org/10.1016/j.petrol.2018.11.002.

10. Song, J.; Wang, Q.; Shaik, I.; Puerto, M.; Bikkina, P.; Aichele, C.; Biswal, S.L.; Hirasaki, G.J. Effect of salinity, $\mathrm{Mg} 2+$ and $\mathrm{SO} 42-$ on "smart water"-induced carbonate wettability alteration in a model oil system. Journal of Colloid and Interface Science 2020, 563, 145-155, https://doi.org/10.1016/j.jcis.2019.12.040.

11. Ali, J.A.; Kolo, K.; Manshad, A.K.; Mohammadi, A.H. Recent advances in application of nanotechnology in chemical enhanced oil recovery: Effects of nanoparticles on wettability alteration, interfacial tension reduction, and flooding. Egyptian Journal of Petroleum 2018, 27, 1371-1383, https://doi.org/10.1016/j.ejpe.2018.09.006.

12. Bernard, G.G.; Arne, M.; Oil, U. Effect of Flood Water Salinity on Recovery of Oil from Cores Containing Clays. SPE-1725-MS 1967, 8, https://doi.org/10.2118/1725-MS.

13. Nowrouzi, I.; Manshad, A.K.; Mohammadi, A.H. Effects of dissolved binary ionic compounds and different densities of brine on interfacial tension (IFT), wettability alteration, and contact angle in smart water and carbonated smart water injection processes in carbonate oil reservoirs. Journal of Molecular Liquids 2018, 254, 83-92, https://doi.org/10.1016/j.molliq.2017.12.144.

14. Rahimi, A.; Honarvar, B.; Safari, M. The role of salinity and aging time on carbonate reservoir in low salinity seawater and smart seawater flooding. Journal of Petroleum Science and Engineering 2020, 187, https://doi.org/10.1016/j.petrol.2019.106739.

15. Ahmadi, S.; Hosseini, M.; Tangestani, E.; Mousavi, S.E.; Niazi, M. Wettability alteration and oil recovery by spontaneous imbibition of smart water and surfactants into carbonates. Petroleum Science 2020, https://doi.org/10.1007/s12182-019-00412-1.

16. Yu, M.; Zeinijahromi, A.; Bedrikovetsky, P.; Genolet, L.; Behr, A.; Kowollik, P.; Hussain, F. Effects of fines migration on oil displacement by low-salinity water. Journal of Petroleum Science and Engineering 2019, 175, 665-680, https://doi.org/10.1016/j.petrol.2018.12.005.

17. Moghadasi, R.; Rostami, A.; Hemmati-Sarapardeh, A.; Motie, M. Application of Nanosilica for inhibition of fines migration during low salinity water injection: Experimental study, mechanistic understanding, and model development. Fuel 2019, 242, 846-862, https://doi.org/10.1016/j.fuel.2019.01.053.

18. Ghasemian, J.; Riahi, S.; Ayatollahi, S.; Mokhtari, R. Effect of salinity and ion type on formation damage due to inorganic scale deposition and introducing optimum salinity. Journal of Petroleum Science and Engineering 2019, 177, 270-281, https://doi.org/10.1016/j.petrol.2019.02.019.

19. Ezzati, S.; Khamehchi, E. Sandstone Reservoir Wettability Alteration Due to Water Softening: Impact of Silica Nanoparticles on Sand Production Mechanism. Biointerface Research in Applied Chemistry 2020, 5 , 6328-6342, https://doi.org/10.33263/BRIAC105.63286342.

20. Hou, B.; Zhang, R.; Chen, M.; Kao, J.; Liu, X. Investigation on acid fracturing treatment in limestone formation based on true tri-axial experiment. Fuel 2019, 235, 473-484, https://doi.org/10.1016/j.fuel.2018.08.057. 
21. Wang, H.; Sharma, M.M. The Role of Elasto-Plasticity in Cavity Shape and Sand Production in Oil and Gas Wells. SPE-187225-PA 2019, 24, 744-756, https://doi.org/10.2118/187225-PA.

22. Hosseinzade Khanamiri, H.; Baltzersen Enge, I.; Nourani, M.; Stensen, J.Å.; Torsæter, O.; Hadia, N. EOR by Low Salinity Water and Surfactant at Low Concentration: Impact of Injection and in Situ Brine Composition. Energy \& Fuels 2016, 30, 2705-2713, https://doi.org/10.1021/acs.energyfuels.5b02899.

23. Mugele, F.; Bera, B.; Cavalli, A.; Siretanu, I.; Maestro, A.; Duits, M.; Cohen-Stuart, M.; van den Ende, D.; Stocker, I.; Collins, I. Ion adsorption-induced wetting transition in oil-water-mineral systems. Scientific Reports 2015, 5, https://doi.org/10.1038/srep10519.

24. Tamilvanan, S.; Gill, S. Candidiasis management: current status of allopathic drugs and utility of corianderbased oil-less emulsions. Letters in Applied NanoBioScience 2019, 8, https://doi.org/10.33263/LIANBS83.586590.

25. Najafpour, M.M.; Amini, E.; Madadkhani, S. Nano-sized manganese oxide coated sea sand: A new wateroxidizing catalyst. International Journal of Hydrogen Energy 2016, 41, 22866-22875, https://doi.org/10.1016/j.ijhydene.2016.08.030.

26. Martínez-Jiménez, M.; Saint-Martin, H. A Four-Site Molecular Model for Simulations of Liquid Methanol and Water-Methanol Mixtures: MeOH-4P. Journal of Chemical Theory and Computation 2018, 14, 25262537, https://doi.org/10.1021/acs.jctc.7b01265.

27. Mohammadi, H.; Jerauld, G. Mechanistic modeling of the benefit of combining polymer with low salinity water for enhanced oil recovery. SPE 153161-MS 2012, 11, https://doi.org/10.2118/153161-MS.

28. Henthorne, L.; Pope, G.A.; Weerasooriya, U.; Llano, V. Impact of Water Softening on Chemical Enhanced Oil Recovery Project Economics. SPE-169165 MS 2014, https://doi.org/10.2118/169165-MS.

29. Tan, P.; Jin, Y.; Yuan, L.; Xiong, Z.Y.; Hou, B.; Chen, M.; Wan, L.M. Understanding hydraulic fracture propagation behavior in tight sandstone-coal interbedded formations: an experimental investigation. Petroleum Science 2019, 16, 148-160, https://doi.org/10.1007/s12182-018-0297-z.

30. Al-Anssari, S.; Arif, M.; Wang, S.; Barifcani, A.; Lebedev, M.; Iglauer, S. CO2 geo-storage capacity enhancement via nanofluid priming. International Journal of Greenhouse Gas Control 2017, 63, 20-25, https://doi.org/10.1016/j.ijggc.2017.04.015.

31. Kim, I.; Worthen, A.J.; Lotfollahi, M.; Johnston, K.P.; DiCarlo, D.A.; Huh, C. Nanoparticle-stabilized emulsions for improved mobility control for adverse-mobility waterflooding. USA. SPE-179644-MS 2016, 10, https://doi.org/10.2118/179644-MS.

32. Ferreira, R.D.; Rodrigues, E.; Martines, M.A.U. Synthesis and characterization of magnetic nanoparticles of cobalt ferrite coated with silica. Biointerface Research in Applied Chemistry 2019, 10, 4908-4913, https://doi.org/10.33263/BRIAC101.908913.

33. Arsalan, R.; Ehsan, K. Effect of alkalinity on sand production due to optimized smart water based on the scale minimization: impact of silica nanoparticles. Biointerface Research in Applied Chemistry Journal 2020.

34. Mishra, S.; Ojha, K. Nanoparticle induced chemical system for consolidating loosely bound sand formations in oil fields. Journal of Petroleum Science and Engineering 2016, 147, 15-23, https://doi.org/10.1016/j.petrol.2016.05.005.

35. Alhuraishawy, A.K.; Bai, B.; Wei, M.; Geng, J.; Pu, J. Mineral dissolution and fine migration effect on oil recovery factor by low-salinity water flooding in low-permeability sandstone reservoir. Fuel 2018, 220, 898907, https://doi.org/10.1016/j.fuel.2018.02.016.

36. Afshin, B.; Ehsan, K Interfacial Phenomena Effect on Sand Production Due to Optimized Smart Water with/without the Presence of Nanoparticles. Biointerface Research in Applied Chemistry 2020, 10, 66526668.

37. Huang, T.; Crews, J.B.; Willingham, J.R. Nanoparticles for formation fines fixation and improving performance of surfactant structure. IPTC-12414-MS 2003, https://doi.org/10.2523/IPTC-12414-MS.

38. Pathak, J.; Sonker, A.S.; Singh, V.; Kumar, D.; Sinha, R.P. Synthesis of silver nanoparticles from extracts of Scytonema geitleri HKAR-12 and their in vitro antibacterial and antitumor potentials. Letters in Applied NanoBioScience 2019, 8, https://doi.org/10.33263/LIANBS83.576585.

39. Rivet, S.; Lake, L.W.; Pope, G.A. Coreflood investigation of low-salinity enhanced oil recovery. SPE-134297-MS 2010, 20, https://doi.org/10.2118/134297-MS.

40. Zhang, Y.; Xie, X. X.; Morrow, N.R. Waterflood performance by injection of brine with different salinity for reservoir cores. SPE-109849-MS 2007, 1-12, https://doi.org/10.2118/109849-MS.

41. Moradi, S.; Isari, A.A.; Bachari, Z.; Mahmoodi, H. Combination of a new natural surfactant and smart water injection for enhanced oil recovery in carbonate rock: Synergic impacts of active ions and natural surfactant concentration. Journal of Petroleum Science and Engineering 2019, 176, 1-10, https://doi.org/10.1016/j.petrol.2019.01.043. 